\title{
Evaluation of the Environmental, Social Effects for the Egyptian National Railways Restructuring
}

\author{
Mahmoud Ahmed Mousa Ali' ${ }^{1}$, Mohamed Abdelnaby El Sayed ${ }^{2}$ \\ ${ }^{1}$ Department of Civil Engineering, Faculty of Engineering, Minia University, Minia, Egypt \\ ${ }^{2}$ Department of Track and Railway Operations, Technical University of Berlin, Berlin, Germany \\ Email: mahmoud mousa78@yahioo.com
}

Received 23 December 2014; accepted 10 January 2015; published 16 January 2015

Copyright (C) 2015 by authors and Scientific Research Publishing Inc.

This work is licensed under the Creative Commons Attribution International License (CC BY). http://creativecommons.org/licenses/by/4.0/

c) (7) Open Access

\section{Abstract}

This paper presents the main findings of the environmental and social impact assessment (ESIA) for the Egyptian national railways restructuring. This paper consists of the two parts: 1) modernizing the signaling system on the Arab El Raml-Alexandria Line and creating a Central Traffic Management Center in Tanta; and 2) renewing $200 \mathrm{~km}$ of track in Lower and Upper Egypt. The purpose of this evaluation is to identify and examine the potential socio-cultural, economic, and physical impacts of the railway restructuring, and propose measures to mitigate its adverse impacts, and develop plans for managing and monitoring the environmental aspects of the railway restructuring. This paper describes outlines of the environmental and social sensitivities of the railway restructuring area, potentially significant impacts of the proposed project and plans for their mitigation. Detailed information on the environmental and socio economic settings of the railway restructuring, components and activities of the proposed project and the results of the environmental and social impact assessment studies are presented in the body of the paper.

\section{Keywords}

Railway, Railway Restructuring, Environmental, Quality, Socio Economic, Volume of Populations

\section{Introduction}

The Egyptian National Railways (ENR) is worked on developing a program for modernization investment from 2007 to 2011, which will finance improvement of signaling and telecommunications facilities and replacing certain sectors of the tracks in upper and lower Egypt. A comprehensive study was undertaken in 2005 to define 
the strategy and scope for the required modernization. The proposal of the railway restructuring, which is covered by the (ESIA), has been developed on the basis of that strategy [1]. It consists of the following two components:

Part 1: This part of the Egyptian national railways restructuring will consist of the signaling systems from Arab el-Raml to Alexandria and centralized traffic control (CTC) for that section and Cairo-Banha (on the Cairo-Alexandria line). The section was selected on the basis of a multi-criteria assessment of the network giving special attention to congestion levels and safety situation. When completed, this section will be the most modern part of the Egyptian railway network in terms of signaling and safety standards.

The Cairo-Alexandria railway line, $208 \mathrm{~km}$ long, is one of the main lines of ENR. Now ENR service operates on the Northeast Corridor similarly to other Northwest Corridor regional services. Each major city has a central train station. In Cairo, it is Ramses Square; and in Alexandria, it is Sidi Gaber and Masr station. The daily number of passenger trains operating on the line is 65 in each direction. Some of these 32 are express trains (airconditioned trains, mixed trains, and those that are not air-conditioned) that operate on the whole distance between Cairo and Alexandria. The other 33 are local trains that operate between one point and another on the line [2]. The line has the highest passenger density (200 to 214 thousands passenger per day) of the entire ENR lines. It can be seen that the all number of trains from Cairo to cities locate in the Cairo/Alexandria corridor. However, there are about 30 trains passing between Cairo to Alexandria.

Modernize the signaling system on the Arab El Raml-Alexandria line and create a Central Traffic Control Center in Tanta (CTC) (Figure 1). This component of the part consists of modernization of basic elements of the signaling systems. It includes introducing a modern Electronic Interlocking System (EIS) to replace the existing electromechanical system. The component also includes the upgrading of Central Traffic Management Center in Tanta, which will control all operation of the entire line. The Tanta Traffic Control Tower will be linked with 11 dispatcher towers along the line (including four new towers) through a network of optic fibers for transmission of telecommunication signals. The new, computerized CTC facility will be provided with two $11 \mathrm{kV}$ power supply units, with auxiliary diesel generators for all control towers of the line. The system will include the modernization of automated counter flow junctions and signaling. It will also include the automation of level crossings to improve the safety and operation efficiency through the introduction of automatic, visual and audio signaling and gate operation and an automatic train approach control system. Also communication and power cables will run parallel to the tracks and no less than two meter on either side. The cables will be placed at least

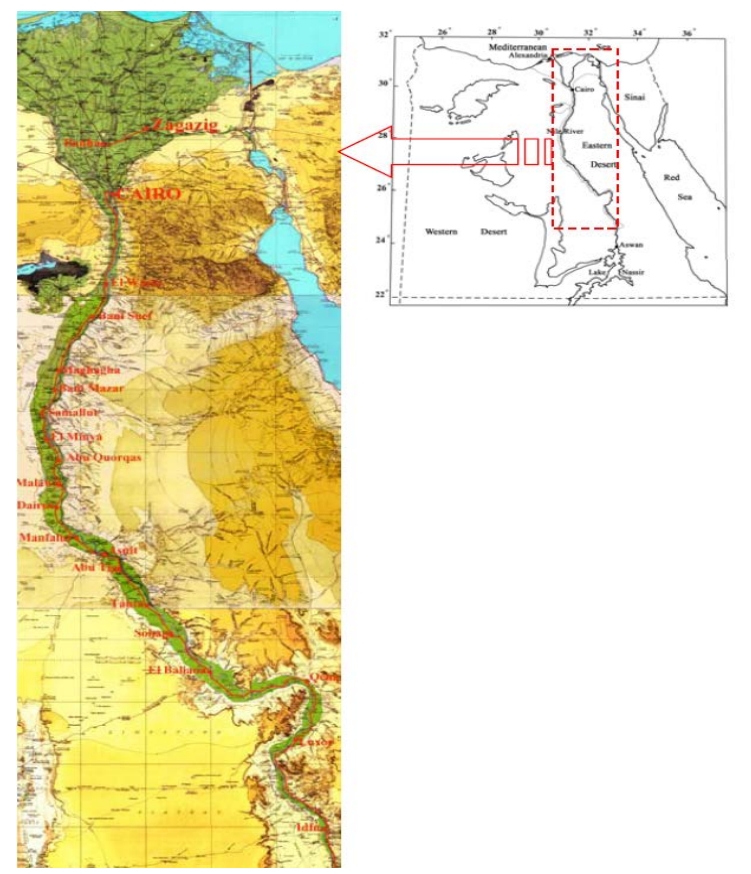

(a)

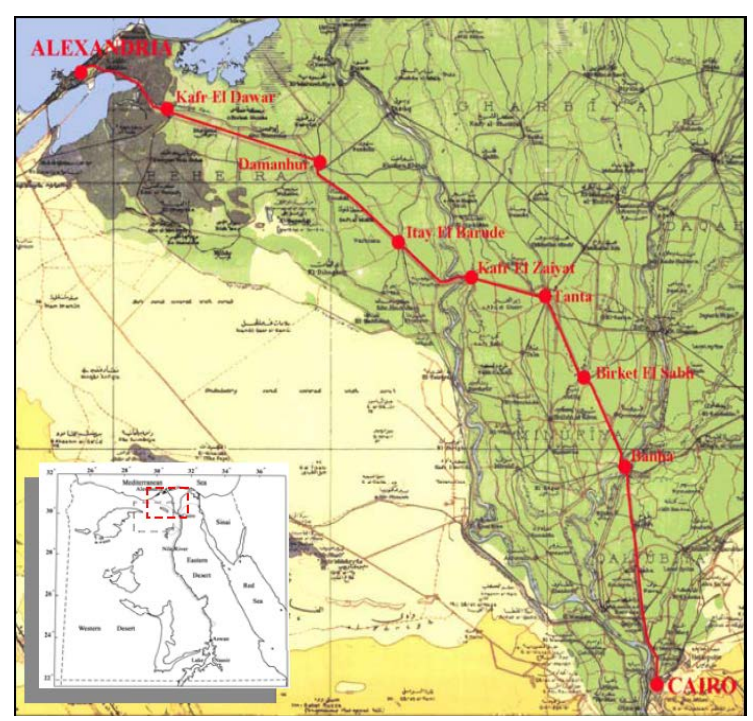

(b)

Figure 1. Geographical locations of the Part 1 and Part 2. 
one meter below the ground surface. The process for laying the cables will be largely automated and highly efficient requiring only limited interruption in the operation of the line and its facilities. Cables will also run under water to cross the Nile and Major Irrigation canals at five locations.

In addition, the Egyptian national railways restructuring will be under this component, a computerized CTC, offering sophisticated information to railway staff, including: 1) command and monitoring of train circulation; 2) a presentation-of-train graph; 3) event recording, and 4) dispatcher communications.

Part 2: the second part of the Egyptian national railways restructuring is track-replacing works for $200 \mathrm{~km}$ of track tracks in upper and lower Egypt (Figure 1). Track section is along the Cairo-Aswan line in upper Egypt (149 km on four sections of track) and the Benha-Port Said line in lower Egypt (51 km on two sections of track), and supervision of those works [3]. Railway ballast track to be renewed have been identified based on the current conditions, traffic levels, and contiguity with track in similar condition. The track structure of the identified sections will be fully renewed; including construction of the new track, i.e., consist of U-I-C 54 rails of continuous-welded rail, concrete sleepers, elastic fastenings, and ballast. The renewal of track system could be helpful to significantly decrease the risk of derailments and decrease track maintenance cost, therefore increasing train speed (notably through elimination of speed restrictions due to the best quality of track).

The Egyptian national railways restructuring project is intended to enhance the efficiency and safety of operation of the Egyptian railway system. The impact factors of the project that affect the fulfillment of these objectives, and their environmental cost are therefore considered in this analysis. Areas to be mostly affected by the project are based upon the relative advantage of the new facilities introduced into the railway lines in terms of efficiency of use of existing conventional lines, increasing train speed and reduction of trip time, improvement of operation safety, and reduction of noise level.

\section{Objectives and Description of the Egyptian National Railways Restructuring}

Railway system was established in 1852 and has since played a major role in transporting passengers and cargo throughout Egypt's various governorates and districts. The Egyptian railway was designed for the movement of passenger and single car-shipments over a network connecting all of Egypt's major cities and traffic generators. The system, for the most part, serves the Nile Valley and the delta. Because of the deserts and seas surrounding Egypt, the railway operates as an isolated system. The Egyptian Railway Authority was established in 1956 as a semi-autonomous agency responsible to the Ministry of Transport and Communications, whereas the railway was previously operated as a government department.

The railway sector plays a significant role in the Egyptian economy and is an essential mode of transport for low-income people. Railway sector in Egypt is managed and operated by Egyptian National Railways created in 1980. It is responsible for managing the railway infrastructure and operates railway transport services on the entire network. In 2010, the railway network measures about $5195 \mathrm{~km}$ of track line between cites, and serves the main activity and population centers in Egypt, consisting entirely of standard gauge track. The railway also carried heavy passenger traffic, especially in Lower Egypt. In many cases, lines operated close to their design capacity, and freight services suffered the effects of severe congestion. Furthermore, passenger traffic was growing more rapidly than freight. Nevertheless, freight revenue, which was once as great as passenger revenue was only half as great in the mid-1980. However, in the year 2004 the revenue of passenger traffic increased more than 2/3 from the freight revenue [3]. Egyptian National Railways consider the largest in transportation of passengers and freight, and is considered the backbone for transportation people in Egypt, where the volume of passenger transport by rail about 1.5 million passenger daily, and 12 million ton of freight [4]. Railway operations became a matter of deep concern to the Government due to several issues, in particular, acute safety issues, deteriorating quality of service, and the significant impact of the sector on the public budget.

At the present time, the entire network of transportation is covered with a microwave telecommunication system allowing voice communications between dispatchers (located in ten regional traffic control centres) and train drivers, and between regional offices and the headquarters in Cairo. An electric color-light, Table 1 the Automatic Block Signaling System is installed on the railway lines for the part of Arab El Raml-Alexandria Line [5].

While most of the network operates by outdated mechanical traffic control systems, the following lines are equipped with central traffic control systems (Table 1):

- Cairo/Qaluib.d 
Table 1. Automatic block signaling system in the Arab El Raml-Alexandria Line.

\begin{tabular}{ccc}
\hline From/to & Distance $(\mathrm{km})$ & Installation \\
\hline Cairo/Alexandria & 208 & Installed in 1980 and 1978 \\
Giza/Beni Suef & 125 & Installed in 1990 \\
Cairo/Giza/Bortos & 31 & Installed in 1984 \\
Asyut/Sohag & 90 & Installed in 1962 and modified for double track in 1990 \\
El Manashi/Etay El Baroud & 122 & Installed in 1986 \\
Abu Qir line & 19 & Installed in 1988 \\
Kobri El Limoun/El Tawdeeb & 5 & Installed in 1998 \\
Qaliub/Shibin El Qanater & 18 & ELS system under construction \\
\hline
\end{tabular}

- Qaluib/Benha

- Cairo/Giza/Bortos.

- El Manashi/Etay El Baroud.

- Giza/Beni Suef.

In addition, certain sectors of the railway tracks in both upper and lower Egypt have been in service beyond their safe operation age according to the ENR standards. The deteriorating conditions of the tracks in these sectors pose an operational risk that requires reducing train speed and their frequent repair needs contribute to train delays. ENR is currently developing a 2007 to 2011 modernization investment program, which will finance improvement of signaling and telecommunications facilities and replacing certain sectors of the tracks in upper and lower Egypt.

\section{Analysis of Alternatives Proposed}

There are two levels of analysis of alternatives have been undertaken of the railway restructuring for each part component. First scenario is considered, implementation alternative and the no action alternative. The two alternatives will be analyzed and discussed. At the second level of analysis, the preferred alternative is subjected to further analysis of alternatives. In this analysis the relative environmental and social merits of elements and activities of the selected project alternative are considered. These alternatives are evaluated and compared, and the optimal one selected. These may include alternative designs, construction methods, building material, and management systems, as appropriate

\section{Part 1:}

\section{Alternative I: non-implementation of the project}

To continue operating the Cairo-Alexandria line with the existing signaling system, with its frequent breakdowns and inefficient operational capabilities places a major additional burden on the ENR's efforts to improve its services to the public and to overcome its major financial difficulties. Many of the present financial difficulties also stem from the frequent breakdowns of the existing systems, and the resulting uneconomical use of the lines and its equipment. It is expected that difficulties facing ENR will grow worse if not addressed now and will become more difficult and more costly to resolve without the implementation of the proposed project. Without the project, the railway service on the Cairo-Alexandria line will further deteriorate affecting the millions of users of that vital line.

\section{Alternative II: Implementation of the proposed project}

The railway restructuring project will provide the badly needed modernization and replacement of elements of the outdated electromechanical signaling system along this most important railway line in the Egyptian railway network. The implementation of the project will benefit the very large number of users of that line, which averages of close to 120 million passengers per year [6]. Once completed, the project will improve the railway service of the Cairo-Alexandria line considerably. Positive impacts of the project on the railway service include the following:

- Improved train operation safety. 
- Improved operation safety of level crossings.

- Reducing trip time as a result of increased train travel speed,

- Will allow more trains to safely use the line per unit time, and will reduce operational delays.

- Increase comfort as a result of smoother train movement and reduced noise levels.

Although the economic cost of the proposed project is relatively high, the ENR that the modernization of the existing, outdated system is highly justifiable to ensure the safe and efficient operation of the railway service along that line. On the other hand, the ENR sees the modernization of the signaling system as an inevitable action that has to be undertaken sooner or later. The operation of the highly efficient modern system will also reduce cost of operation per traffic unit and will contribute to the ENR's efforts to reduce loses and increase revenue generating potential. But there are many a number of negative impacts are expected during the construction phase of the railway restructuring project.

\subsection{The First Project Component}

Modernizing the signaling system on the Arab El Raml-Alexandria Line and creating a Central Traffic Management Center in Tanta, this component of the project consists of modernization of basic elements of the signaling systems covering the following components (Figure 2):

a) Full new automatic block signaling system (with contraflow signaling) with color light signals between Arab El Raml and Alexandria.

b) Remote control of signaling equipment

c) Electronic Interlocking Systems

d) Full new automatic level crossings, not including civil works, between Arab El Raml and Alexandria

e) Assembling of Cables and cabling equipments related with all signaling and telecommunication systems

f) CTC computer based Command Center, including definition of non-proprietary "CTC interface protocol”

g) Diagnosis systems for all components

h) Tests of system and put into service of the system

i) Complete power supply system with SCADA (Supervisory Control and Data Acquisition) management system

j) Preventive maintenance (level 1, level 2 and level 3)

k) Training of operation and maintenance staff

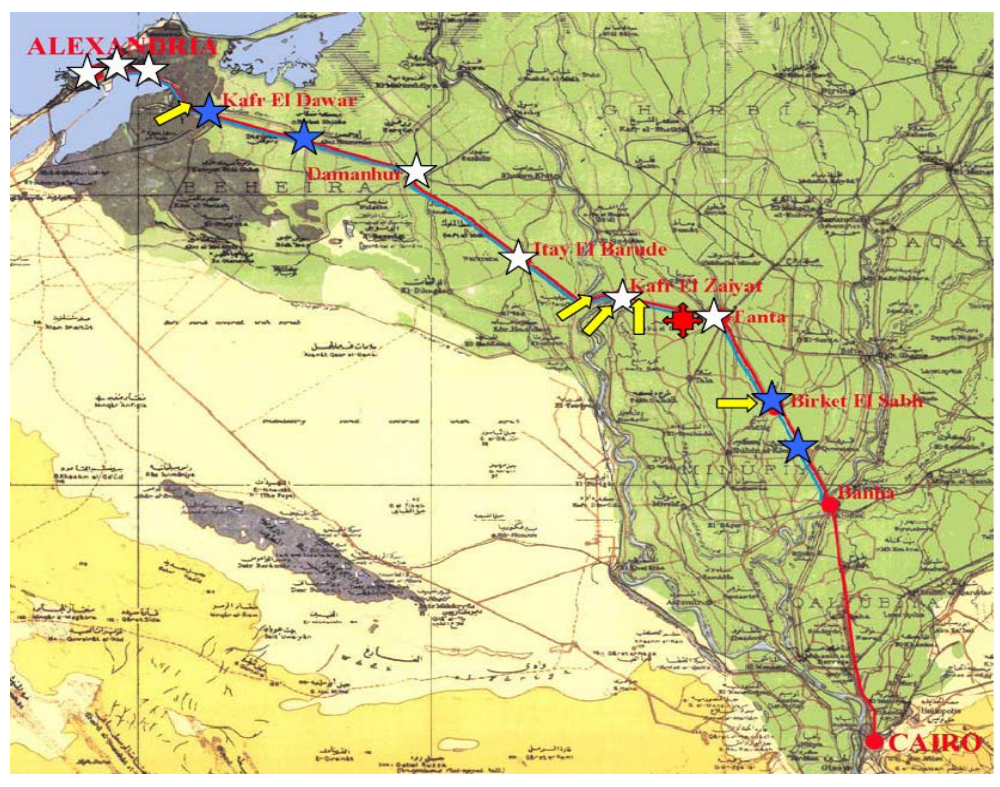

Figure 2. The Cairo-Alexandria railway line (red line) and the Arab El Raml-Alexandria signaling system upgrading sector (blue line), showing the approximate locations of existing dispatcher towers $(\boldsymbol{c})$ ), proposed dispatcher towers $(\vec{\hbar})$, draw bridges $(\vec{\nabla})$ and the Tanta traffic control center. 
The following concepts and main requirements will be used for the elaboration of the preparation of the functional specifications and the preliminary design of the signaling system on Arab El Raml-Alexandria corridor.

- Signaling system, protection systems in level crossings, train and security brake systems to be established will be in conformity with $160 \mathrm{~km} /$ hour train speed

- Signal system will be SSI (Solid State Interlocking) and will be designed in modular systems

- CTC center and Local Command Console functions (command and monitoring, evaluation, presentation of train graph, information event recording system, dispatcher communication system, uninterrupted power supply, etc.)

- Main characteristics of track circuits (type of track circuits to be used, ballast impedance, detection of complete section rail broken) and of switch engines (mode of connection to interlocking to provide a safe locking, type of operating energy, manual operation included, etc.)

- Main characteristics of protection system of level crossing standards, adjustable and synchronous informing time to be maintained according to train speed and/or train existence, lighted and noised warning devices to be used in all level crossing protection systems, for level crossings determined by ENR barrier handled protection devices to be used, etc.)

- Energy of signal equipment between stations will be provided from uninterrupted power source;

- Energy of CTC and stations shall be provided from two independent sources. In case of interruption of the main power system, CTC and stations (vital functions) shall be fed by uninterrupted power source over buffer charged accumulators that can give steady energy

- Main characteristics of communication cables (fiber optic option to be evaluated) and of signal cables will be described

- Transmission and communication systems main characteristics to provide voice and data transmission on fiber-optic cable for telecommunication and signaling installations and computer systems

- Diagnosis system for controlling the status of all components and reporting to the maintenance center (Figure 3)

At the present time, there are seven dispatcher towers. These are the Tanta, Kafr El Zaiyat, Itay El Barude, Damanhour, Sidi Gabir, El Hadra and Alexandria towers. Four additional towers will be constructed in Qowesna, Birket El Sabh, Abu Homos and Kafr El Dawar. The new, computerized train tracking system will be capable of tracking train by number, type, location, and speed and detecting delays and operation malfunctions. The system will also include the modernization of automated counter flow junctions and signaling.

The system will also include the automation of 53 level crossings to enhance the safe and efficient operation of these vital elements of the railway line. This will include the introduction of automatic, visual and audio signaling and gate operation. The automated level crossing systems will also include the introduction of automatictrain approach control systems. Draw bridges along the line (five bridges) will also be equipped with automated signals to replace the existing electromechanical signaling system.

This new electrolysis system will significantly improve considerably the safety of operation of the Cairo-

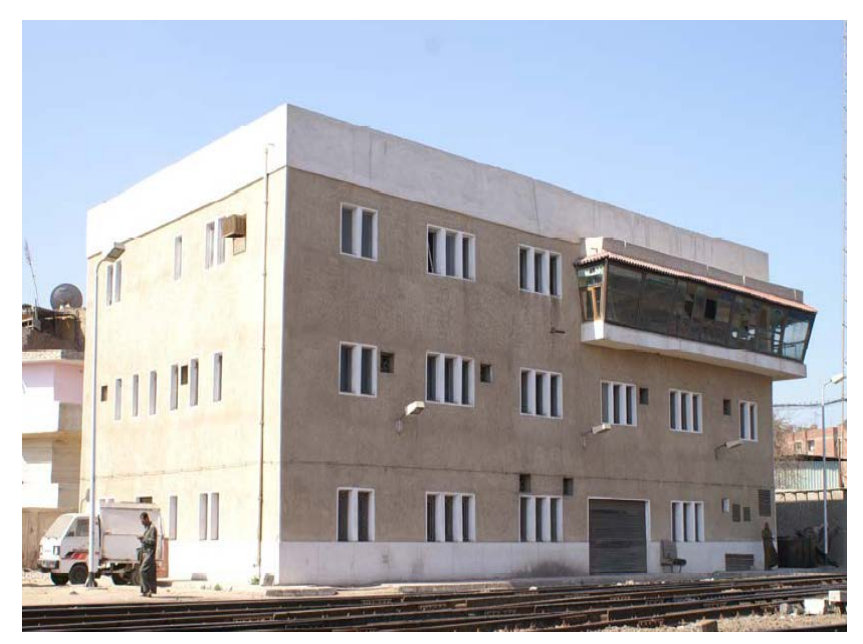

Figure 3. The Tanta traffic control center. 
Alexandria railway line and is expected to reduce accidents caused by human error or failure of the existing, outdated signaling system. It is also expected to allow a much safer operation of the large number of level crossings along this line. As trains average travel speed is expected to increase following the operation of the new signaling system (maximum speed may be as high as $160 \mathrm{~km} /$ hour), accidents which cannot be completely eliminated will have much more destructive consequences. This is particularly true with the often lax control of traffic across level crossings and the frequent, illegal pedestrian crossing of the railway tracks.

\section{Part 2}

\section{Alternative I: non-implementation of the project}

For the second part of the railway restructuring project, not doing anything is absolutely unacceptable. Because all parts of the railway line that had been identified to be replaced, where these parts of the railway are is a major obstacle on the railway operations and ENR it must be avoid this obstacle. Also the Egyptian railways had been contraction, more than 150 years on the Nile Delta and there is chronic underinvestment. Infrastructure and equipment

\section{Alternative II: Implementation of the proposed project}

The replacement of track sections is a necessary procedure in the normal maintenance of railway lines. According to ENR representatives and railway experts, the replacement of some of the sections is long overdue. As a precautionary measure, the ENR operates the trains at slower speeds in track sections based on their conditions. This often results in longer trip times and considerable delays, particularly when large sections of the tracks are in poor conditions as is the case of the Cairo-High Dam and the Banda-Zagazig lines. The adoption of the slow train travel speed tactics along the deteriorating lines adversely affect the economics of the use of the line as fewer trains can use it per unit time. Replacing the sections will allow the trains to operate at the track design speed and hence a more efficient use of the tracks by allowing more trains to use the tracks per day. It will also contribute to allowing passengers, faster, safer, less noisy and more comfortable train service. Replacing track sections is an absolute necessity that is unavoidable in the normal operations of any railway system. But temporary impacts are expected to occur during the construction process. Most of these impacts can be mitigated, and the expected improvements in the rail service as a result of the proposed project greatly outweigh any expected residual impacts.

\subsection{The Second Project Component}

Replacing $200 \mathrm{~km}$ of the tracks in Upper and Lower Egypt, track sections to be replaced through this component of the project are shown in Table 2. This includes sections of the Banha-El Zagazig line in Lower Egypt (23.9 $\mathrm{km}$ westbound and $27.3 \mathrm{~km}$ eastbound) and $148.7 \mathrm{~km}$ in the different sections of the Cairo-High Dam Line in Upper Egypt.

The existing conventional tracks on the Banha-El Zagazig line (construction period 1989-1990) was constructed a ballasted track, i.e., UIC 54 welded rails with concrete sleepers. In the Cairo-High Dam Line (construction period 1983-1988), the existing conventional track was also constructed a ballasted track, i.e., UIC 54 welded are welded rails with wooden or concrete sleepers. The rails will be replaced in these sections with new UIC 54 rails on pre-stressed concrete sleepers using the K-Type rail fastening system, i.e., electrically insulated. The component of old tracks such as (rails, sleepers, etc.) had replaced by the new one and then it was transported by a freight train to ENR storage yards for subsequent storage and disposal. New ballast of basalt gravel will be added to a depth of $30 \mathrm{~cm}$. This layer will be mechanically packed according to the technical specifications until reaching the final designed level. The quantities of ballast required for the replacement of the track sections has not been specified in the project material provided. The project document does not specify the expected source of that relatively large quantity of basalt. However, basalt quarries are found at several areas in the Egyptian desert and have been in use for centuries. The largest are the Abu Zahbal Quarries located just northeast of Cairo, which produce most of the basalt used in the Greater Cairo area. Officials of the ENR clearly stated that new basalt will be used for all construction work of this project.

ENR engineers stated that the normal procedure for track replacement work includes the transportation of old rails and sleepers using flat cars to the ENR storage yards to be subsequently sold. Standard, $18 \mathrm{~m}$ rail sections or pre-welded tracks of $252 \mathrm{~m}$ length will be used. Track segment of (18 m) was transported to the assembly yards in Tanta and Minia. The track segment will then be transported by an assembly train, equipped with flat cars to the installation site. Following the rail installation and the mechanical leveling and packing of the embankment to the design levels, trains will be allowed to run on the new tracks several times before the rails sec- 
Table 2. Track lengths and locations to be replaced.

\begin{tabular}{cccc}
\hline Railway line & From $(\mathrm{km} / \mathrm{m})$ & To $(\mathrm{km} / \mathrm{m})$ & Distance \\
\hline Banha-Zagazig & $7 / 828$ & $31 / 716$ & $23.888 \mathrm{~km}$-westbound \\
Banha-Zagazig & $1 / 100$ & $29 / 148$ & $27.348 \mathrm{~km}$-eastbound \\
Cairo-High Dam & $104 / 930$ & 126 & $21.070 \mathrm{~km}$-southbound \\
Cairo-High Dam & $207 / 500$ & $187 / 500$ & $20.00 \mathrm{~km}$-northbound \\
Cairo-High Dam & $467 / 500$ & $528 / 500$ & $61.00 \mathrm{~km}$-southbound \\
Cairo-High Dam & $541 / 197$ & $467 / 500$ & $46.694 \mathrm{~km}$-northbound \\
\hline
\end{tabular}

tions are welded in a pre-stressed position. Welding of the 18 or 252 meter rail segments will be carried out with the rails in place Rail welding ensures a smoother, less noisy train movement on the tracks.

The replacement of these tracks sections is necessary for the safe operation of the Cairo High Dam Railway Line [7]. The present condition of the tracks in these sections represents an operational hazard to the trains and the adjacent communities. To minimize the potential hazard caused by these old track sections, the ENR adopts operation protocols that include reducing train speed at these sections, which in turn results in longer trip times and a considerably reduced total passenger capacity of the line. This project component, therefore, will alleviate this potential operational hazard and maximize the operation efficiency of the line.

As shown in Figure 4 the all part of the track replacement section in the railway restructure of the Upper Egypt. Figure 4(a) and Figure 4(b) show the track replacement section in the Banha-Zagazig line, and the Cairo-Bani Suef respectively. Figure 4(c) shows the part of replacement section in Maghagha-Samalut sector of El Minia city, and Figure 4(d) shows the last section of replacement between Abu Tig-El Baliana of the Asyut and Sohag cities.

\section{Significant Impacts for Restructuring}

The railway lines of both components of the project run through the most densely populated regions of Egypt. The socioeconomic make-up of the influence area of the project is extremely diverse, and is in fact as varied as that of the Egyptian society. These include affluent communities of high economic sectors of Cairo and Alexandria, as well as poorest of the poor of the Egyptian society in informal urban areas and in remote villages of Upper Egypt. Although the greatest part of the railway tracks run through rural areas where the main economic activity is agriculture, considerable portions of the lines pass through urban areas with highly diverse economic activities.

The railway track corridor cuts across most of the towns it serves, creating a physical barrier that often divides a town into two socio-economically distinct sections. This is caused by the fact that the railway lines were originally placed just outside cites. As cities grew, often informally, the poorer sectors of the urban society gradually settled on the side of the track opposite of the formal town. Informal neighborhoods eventually appeared, conveniently close to the formal city yet separated from it by the railroad embankment. The railway corridor, which is often walled within cities, allow traffic and people crossing at relatively few level crossings,. These level crossings invariably form traffic bottlenecks, particularly in larger, more crowded area. Informal crossings created by breaching the protective walls are extremely common and create a major hazard to its users and the passing trains.

The Cairo-Alexandria railway line runs through the Nile Delta, one of the most densely populated areas in the world, linking the largest population centers in Egypt and several of the country's larger towns. The line provides a railway linkage for the capital cities of six governorates and a total human population of approximately 31 million [2], most of whom live in the urban areas of Cairo and Alexandria and delta towns. It provides a key transportation service for passengers, goods and mail service. Table 3 shows the governorates transected by the Cairo-Alexandria railway line [8].

The Cairo-High Dam railway line links the largest population centers in Upper Egypt to Cairo. The line provides a railway linkage for ten governorates with a total human population about of more than 41 million, a little than one half of whom live in urban areas. Table 4 shows the governorates transected by this line. The line represents the most important transportation service for passengers including tourists traveling archeological attractions of Upper Egypt [9]. The line is also a key transportation artery for cargo within Upper Egypt and be 


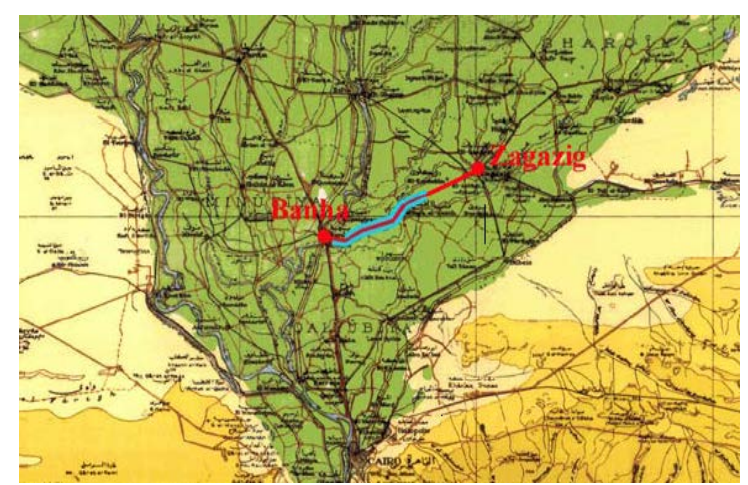

Banha-Zagazig line

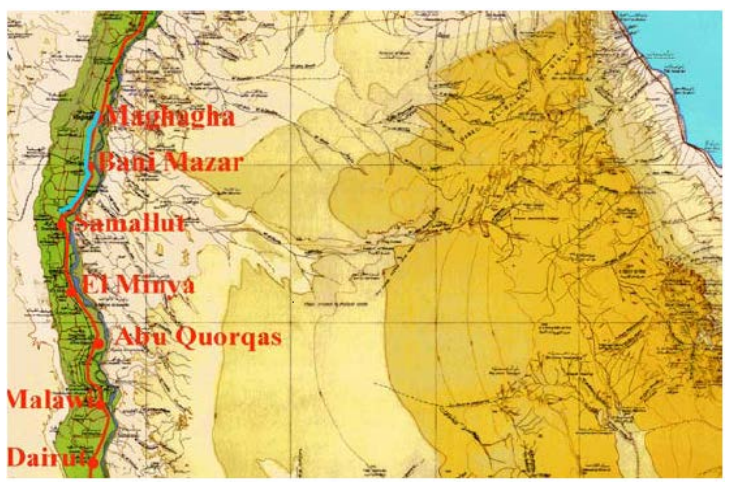

Maghagha-Samalut sector

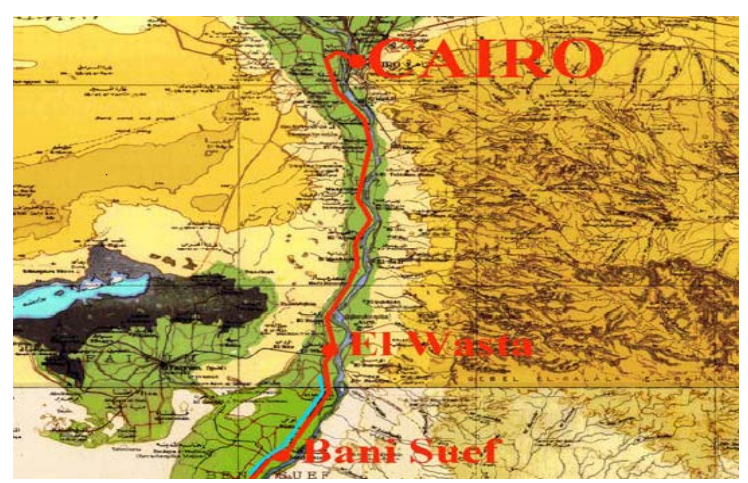

Cairo-Bani Suef sector

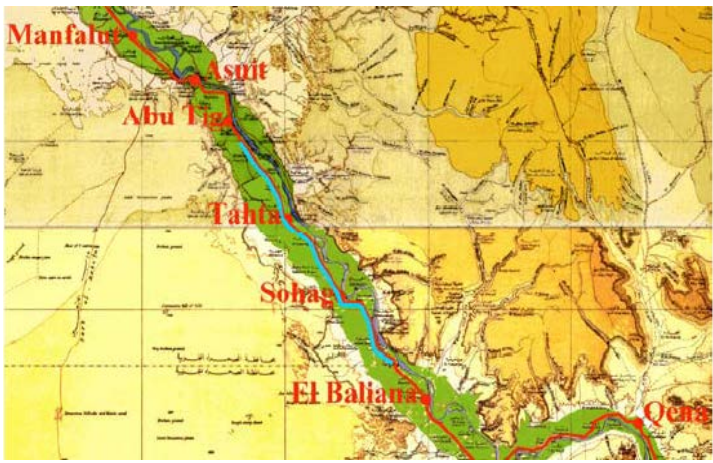

Abu Tig-El Baliana sector of the Cairo-High Dam line

Figure 4. Track replacement sections (blue line) in railway restructure of the upper Egypt.

Table 3. Governorates transected by the Cairo-Alexandria railway line and the size of their urban and rural populations.

\begin{tabular}{cccc}
\hline Government & Urban & Rural & Total \\
\hline Cairo & $7,786,640$ & ---- & $7,786,640$ \\
Alexandria & $4,110,015$ & ---- & $4,110,015$ \\
Qalioubiya & $1,599,230$ & $2,637,773$ & $6,874,776$ \\
Menofia & 668,703 & $2,601,701$ & $3,270,404$ \\
Gharbia & $1,200,752$ & $2,809,546$ & $4,010,298$ \\
Beheira & 907,300 & $3,829,826$ & $4,737,126$ \\
TOTAL & $16,272,640$ & $11,878,846$ & $30,789,259$ \\
\hline
\end{tabular}

tween Upper Egypt and Lower Egypt and Cairo.

\subsection{Environmental and Social Impacts}

Most of these impacts are expected to be affecting both the local populations close to the construction sites as well as the general users of the railway line regardless of where they live. Impacts on the operation of the railway lines during construction will affect larger sectors of the society, particularly those using the train. Impacts on the physical environment and the ecology of the project area appear to be minor.

Accordingly, the Egyptian national will investigate more closely the socio-economic impacts of the construction process and activities of both components of the project. The Egypt railways restructuring covers two impact groups. These are the impacts on users of the train lines (including daily commuters and other passengers), and those that will affect communities residing or working near the construction sites. Accordingly, two types of impacts will be considered in the assessment 
Table 4. Governorates transected by the Cairo-High Dam railway line and the size of their urban and rural populations.

\begin{tabular}{cccc}
\hline Governorate & Urban & Rural & Total \\
\hline Cairo & $7,786,640$ & ----- & $7,786,640$ \\
Giza & $3,676,034$ & $2,596,953$ & $8,869,524$ \\
Beni Sweif & $5,232,539$ & $1,757,988$ & $6,990,527$ \\
Fayoum & 564,596 & $1,948,196$ & $2,512,792$ \\
Minya & 787 & $3,392,728$ & $3,393,515$ \\
Assiut & 906,864 & $2,534,733$ & $3,441,597$ \\
Sohag & 801,360 & $2,945,017$ & $3,746,377$ \\
Qena & 643,097 & $2,358,397$ & $3,001,494$ \\
Luxor & 213,819 & 237,499 & 451,318 \\
Aswan & 502,863 & 681,579 & $1,184,442$ \\
Total & $20,328,599$ & $18,453,090$ & $41,378,226$ \\
\hline
\end{tabular}

1) Generalized impacts: these are widespread impacts that will affect most or the entire influence area of the project component. Examples of such impacts are train delays resulting from construction activities, which will affect the great majority of the commuters and other users of a train line. Assessment of generalized impacts covers, the Cairo-Alexandria and the Cairo-High Dam Lines.

2) Site-specific, local impacts: these impacts will be restricted to specific sites and communities along the railway lines (such as access restriction during construction at certain level crossings, noise, air and water pollution generated during extended construction activities at certain sites.

However, construction work is expected to have a number of adverse impacts on physical elements of the environment which in turn will have significant socio-economic impacts. This construction work will also directly affect large sectors of the populations by affecting the operation of the railway service and its associated elements such as the level crossings. Elements of construction activities that are expected to adversely affect the environment and their direct and indirect impacts are shown in following components:

\subsection{Potential Environmental and Social Impacts}

\begin{tabular}{|c|c|c|}
\hline Activity & Direct impacts & Indirect impact \\
\hline $\begin{array}{l}\text { Construction activities } \\
\text { at areas accessible } \\
\text { to the public. }\end{array}$ & $\begin{array}{l}\text {-Safety risk to public at or near construction sites. } \\
\text {-Generation of dust and noise from construction } \\
\text { activities, vehicles and equipment } \\
\text {-Hazardous emissions (e.g. asphalting, rail welding, } \\
\text { operation of vehicles and other equipment) } \\
\text {-Improper transportation, disposal and/or } \\
\text { decontamination of old ballast basalt may result in } \\
\text { local pollution and visual nuisance }\end{array}$ & $\begin{array}{l}\text {-Safety risk to construction crews and public at or } \\
\text { near construction sites and along material } \\
\text { transportation routes. } \\
\text {-A major nuisance to communities near work site, } \\
\text { particularly if taking place at night. } \\
\text {-Threat to public health in areas adjacent } \\
\text { to work site. }\end{array}$ \\
\hline $\begin{array}{l}\text { Reduction of train } \\
\text { speed at work sites }\end{array}$ & $\begin{array}{l}\text {-Longer train trip time } \\
\text {-Unexpected train delays }\end{array}$ & $\begin{array}{l}\text {-Train delay may result in delayed arrival to } \\
\text { work or business, schools, etc. } \\
\text {-Unexpected delay is more difficult to deal with. } \\
\text {-Some train passenger might have to resort to other, } \\
\text { often more expensive modes of transportation. }\end{array}$ \\
\hline $\begin{array}{l}\text { Construction at level } \\
\text { crossings (Partial or complete } \\
\text { closure of the crossing to } \\
\text { pedestrian and vehicle traffic) }\end{array}$ & $\begin{array}{l}\text {-Increased traffic congestion at certain level crossings } \\
\text {-Interrupting normal movement of people and goods. } \\
\text {-Increased illegal track crossing. }\end{array}$ & $\begin{array}{l}\text {-Traffic flow problems at areas in the general } \\
\text { neighborhood of the level crossing. } \\
\text {-Difficult accessibility to certain areas } \\
\text {-Difficulties of access to emergency } \\
\text { services and vehicles. } \\
\text {-Delay to work, business or schools. }\end{array}$ \\
\hline
\end{tabular}




\subsection{Socio and Economic Impact}

Socio-economic impacts of the project affect the three sectors of potentially impacted communities by. Where expected impacts affecting each one of these communities are covered in this section.

- Local residents of communities adjacent to the train corridor

- Train users

- Level crossing users

During construction, the main potential project impacts are socio-economic impacts of three groups: train users, local residents of communities adjacent to the train corridor, and frequent users of level crossings. Potential socioeconomic impacts on train users include expected delays due to construction work and the potential need to use other modes of transportation during the construction period and impacts related to the operation difficulties resulting from construction work are among the most important impacts of this project. Interruption of the normal operations of the trains directly and indirectly affects a large number of people who depend on trains as a cheap, safe and reliable mode of transportation. Potential impacts on level crossing users include the need to identify and use alternative crossing pathways during construction. Safety of pedestrians and vehicular traffic crossing the tracks at level crossings (or at informal crossing sites) is also an issue that should be taken into consideration. There is certain public safety risks associated with the construction process. These will include those related to the use of heavy construction equipment in areas accessible to the public, as well as the transportation and handling of construction material and larger items such as rails and sleepers through public area. Potential socioeconomic impacts on the local residents of communities adjacent to the train corridor include that noise generated during certain construction activities (e.g., mechanical shaking and sifting of ballast gravel of basaltic fragments during ballast replacement work) will exceed permissible levels. Similarly, certain construction activities (e.g., rail welding, excavation of foundations and cable trenches, etc.) are expected to generate some air pollutants.

\subsection{Impact Reduction of Train Speed at Construction Sites}

Impacts associated with these activities are longer train trip time and unexpected train delays. Some train users may become forced to use other, more costly modes of transportation. In addition, shifting to other transportation modes will reduce the number of train passengers, reducing demand on goods and services offered by businesses in the vicinity of train stations.

\subsection{Construction at Level Crossings, with Partial or Complete Closure of the Crossing to Pedestrian and Vehicle Traffic}

Impacts associated with this activity are increased traffic congestion at certain level crossings, interrupting normal movement of people and goods, and increased illegal track crossing. Impacts also include traffic congestion or reduced traffic flow in areas leading to or from level crossings. This, in turn, will temporarily increase noise and air pollution with vehicle emission of slow moving vehicles. It will also cause problems due to delay in arrival to work, schools, etc.

\subsection{Operation and Maintenance Phase Impacts}

Operation of trains at increased travel speeds as expected following the completion of the signaling modernization and the replacement of old tracks will increase the risk of accidents at level crossings. Risk of accidents will particularly increase to pedestrians crossing at informal crossings which occur in many places all along the lines. This is particularly the case at areas where deteriorating track or signal conditions have, for years required that trains travel at much reduced speeds. Users of informal crossings at these areas who have grown accustomed to the slow train speeds will be exposed to a much great risk with the faster trains. Awareness raising effort will be essential to reduce this risk.

\subsection{Noise}

With the extremely varied activity profile of areas along the two railway lines covered in this study, ambient noise levels and air quality are expected to be equally varied. These levels are expected to vary considerably 
from one area to another along the hundreds of kilometers of railway corridors covered by this project. These values are also expected to change during different seasons and even times of day. In certain areas the ambient levels of noise and air pollutants exceed national permissible standards. It is expected, however, that noise generated during certain construction activities will exceed permissible levels. Noise related to the removal and installation of the tracks, particularly the working of the basalt fragment ballast will be particularly high.

Similarly, certain construction activities (e.g. welding, asphalting, excavation of foundations and cable trenches, etc.) are expected to generate dust and other forms of air pollution. Although these pollutants are expected to be of relatively small quantities, that will quickly disperse and become diluted, community members living very close, or downwind of the work site may potentially be affected. These impacts will also affect construction crews at the worksite. Although these impacts are all temporary in nature, occurring only during the actual construction work, which will mostly be undertaken mostly for a few hours to few days at any given site, mitigation measures are considered to be necessary. Table 5 will be show that, the railway is the second significant source of noise in Egypt cities (road traffic is the first significant source of noise in the city) [10]. Measurements have been carried out to determine levels of railway noise in Egypt City and the effects on the railway noise of: 1) distance between train and receiver; 2) speed of train; 3) height of receiver; 4) length of train; 5) using a barrier; 6) a ban on horn use. So, Table 5 shows the permissible noise levels in different land use areas in Egypt.

\section{Conclusions and Remarks}

On the basis of this study, the Egyptian national railway agency should run resistance to the environmental and social impact and noise control. The adverse impacts of the railway restructure occur during the construction, operation and maintenance phases. Elements of the environmental/social impact mitigation plan are described in detail below.

- Excavation and construction material should be covered so as to minimize spillage and generation of dust.

- As much as practically possible, construction material martial and waste should be transported to and from construction sites using cargo trains.

- Vehicles delivering construction material to, or removing construction waste from the work sites, should be covered to avoid material spillage.

- Vehicles uploading material should maintain the lowest possible fall height to reduce noise and dust generation.

- All construction activities should be carried out during the day time hours to minimize noise disturbance to communities near work sites.

- Workers exposed to noise exceeding permissible levels (e.g. ballast uploading) should wear hearing protection.

- Construction waste should be disposed at dumpsites designated by local governments

- Storage of construction material should be allowed only at ENR designated sites or ENR's storage yards in a

Table 5. Maximum permissible noise levels in different land use areas in Egypt.

\begin{tabular}{|c|c|c|c|c|c|c|}
\hline \multirow[t]{4}{*}{ Type of area } & \multicolumn{6}{|c|}{ Permissible limit for noise intensity decibel } \\
\hline & \multirow{2}{*}{\multicolumn{2}{|c|}{$\begin{array}{c}\text { Day } \\
(7 \mathrm{am}-6 \mathrm{pm})\end{array}$}} & \multirow{2}{*}{\multicolumn{2}{|c|}{$\begin{array}{c}\text { Evening } \\
\text { (6 - } 10 \mathrm{pm})\end{array}$}} & \multicolumn{2}{|c|}{ Night } \\
\hline & & & & & $(10 \mathrm{pn}$ & am) \\
\hline & From & To & From & To & From & To \\
\hline Commercial, administrative and downtown areas & 55 & 65 & 50 & 60 & 45 & 55 \\
\hline $\begin{array}{l}\text { Residential areas in which can be found some workshops } \\
\text { or commercial establishments or located on a main road }\end{array}$ & 50 & 60 & 45 & 55 & 40 & 50 \\
\hline Residential areas in the city & 45 & 55 & 40 & 50 & 35 & 45 \\
\hline Residential suburbs with low traffic & 40 & 50 & 35 & 45 & 30 & 40 \\
\hline Residential rural areas, hospitals and gardens & 35 & 45 & 30 & 40 & 25 & 35 \\
\hline Industrial areas (heavy industries) & 60 & 70 & 55 & 65 & 50 & 60 \\
\hline
\end{tabular}


way that will not affect traffic or pose any risk to communities adjacent to the railway corridors.

- Construction scheduling should be discussing to reduce the delay of train delays and associated adverse impacts. A construction schedule based on restricting work to one of a number of predetermined construction sector at one time should be a scheduling requirement. The expected "scheduled trip delay" should not exceed about 30 minutes.

- Train re-scheduling should be undertaken, taking into account the expected delays and showing new departure and arrival times during the construction work

- Work should be so planned as to avoid the complete blockage of any level crossing, as much as practical.

- Concentrating work in level crossings during times of reduced traffic, possibly during the night, as long as noise level can be kept at a legally permissible level.

- Management of vehicle and pedestrian traffic at level crossings should be improved.

- Protective walls of railway corridor in densely populated area should be repaired and regularly inspected and maintained to prevent informal crossing.

- A public awareness campaign on railway safety should be designed and implemented.

The noise grants should be offered to improve the sound insulation of facades to ensure low noise indoors. The noise abatement programme must be based on priority schemes ensuring that houses with the highest noise impact must be given priority. A ban is on using horns on trains passing inside the city and we can increase the typical distance between track centerline of train and the nearest noise sensitive buildings. Other noise control countermeasures could include operational countermeasures such as re-routing or a limitation on night traffic, rolling stock improvement with composite brake blocks or optimized wheels, rail grinding, and tuned absorbers on tracks.

\section{References}

[1] Egyptian Railways (2005) Diagnosis of the Present Situation and Restructuring Strategy (August 2005).

[2] El-Sayed Al-Tony, F. and Abdelkader Lashina (2000) Cost-Benefict Analysis of Railway. Electrification: Case Study for Cairo-Alexandria Railway Line. Impact Assessment and Project Appraisal, 18, 323-333. http://dx.doi.org/10.3152/147154600781767312

[3] The World Bank (2005) Restructuring Egypt Railways, Egypt Public Expenditure, Policy Note 4, Review August 2005.

[4] Deborah Matherly: Egypt Railway Study (2009) Technical Assistance for Safety Improvements AND RAIL Traffic Management. Transportation research Board of the National Academies, Nr. 15, 13.

[5] Egypt State Information Service (2007) Year Book (2007).

[6] The World Bank (2009) Egyptian National Railways Restructuring Project Report, Report No: AB2433, February 26, 2009.

[7] (2008) Report of the Environmental Impact Assessment. May 2008.

[8] CAPMAS (2012) Central Agency for Population Mobilization and Statistics. Population Estimates by Sex \& Generate 1/1/2012, Egypt in Figures 2012, March 2012.

[9] Description of Egypt in Numbers (2007) Publication of the Information and Decision Support Center, Cabinet of Ministers.

[10] Ali, S.A. (2004) Investigation of the Dose-Response Relationship for Road Traffic Noise. Department of Architecture, Faculty of Engineering, Assiut University, Assiut, Egypt Applied Acoustics, in press Egyptian Environmental Law No. 4. Egyptian Ministry of Environment, Cairo, Egypt, 1994. 
Scientific Research Publishing (SCIRP) is one of the largest Open Access journal publishers. It is currently publishing more than 200 open access, online, peer-reviewed journals covering a wide range of academic disciplines. SCIRP serves the worldwide academic communities and contributes to the progress and application of science with its publication.

Other selected journals from SCIRP are listed as below. Submit your manuscript to us via either submit@scirp.org or Online Submission Portal.
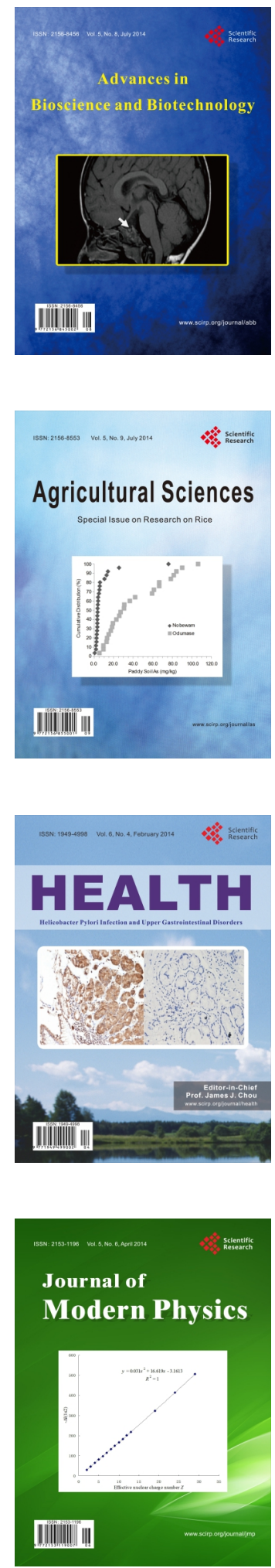
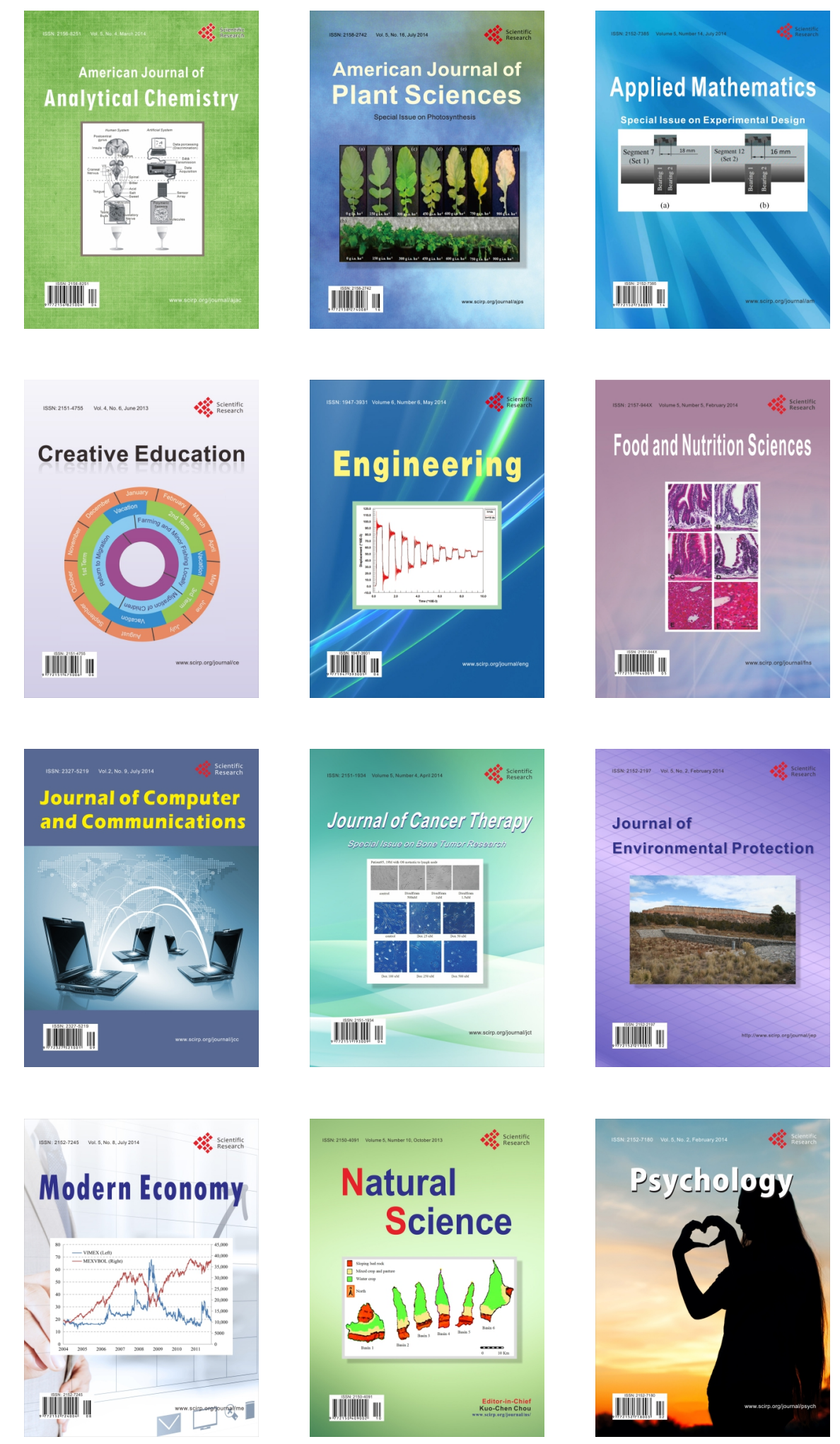